\title{
Artelogie
}

Recherche sur les arts, le patrimoine et la littérature de l'Amérique latine

$17 \mid 2021$

Transformaciones en Cuba contemporánea: cultura y sociedad

\section{Compte rendu de l'ouvrage de Christine Frérot, Amériques intimes et autres récits, Paris, Ginkgo éditeur, 2021, 87p.}

Élodie Vaudry

\section{OpenEdition}

\section{Journals}

Édition électronique

URL : https://journals.openedition.org/artelogie/9719

DOI : $10.4000 /$ artelogie.9719

ISSN : 2115-6395

Éditeur

Association ESCAL

Référence électronique

Élodie Vaudry, «Compte rendu de l'ouvrage de Christine Frérot, Amériques intimes et autres récits, Paris, Ginkgo éditeur, 2021, 87p. », Artelogie [En ligne], 17 | 2021, mis en ligne le 07 septembre 2021, consulté le 15 septembre 2022. URL : http://journals.openedition.org/artelogie/9719 ; DOI : https://doi.org/ 10.4000/artelogie.9719

Ce document a été généré automatiquement le 15 septembre 2022.

Tous droits réservés 


\title{
Compte rendu de l'ouvrage de Christine Frérot, Amériques intimes et autres récits, Paris, Ginkgo éditeur, 2021, 87p.
}

\author{
Élodie Vaudry
}

"L'exote sait que la rencontre avec l'Autre n'est réelle, et donc féconde, qu'à condition de s'y impliquer corps et âme $»^{1}$ sont les mots de Jean Mouttapa que Christine Frérot choisit pour introduire le lecteur dans son ailleurs. Amériques intimes et autres récits traite avec justesse de la relation charnelle et spirituelle, mais aussi intellectuelle que la chercheur entretient avec les terres latino-américaines. Auteur de nombreux ouvrages sur le Mexique, notamment Échanges artistiques contemporains. La France et le Mexique (1996), Fictions mexicaines. 38 témoins de l'art du XX $X^{e}$ siècle (2016), critique d'art pour la revue Art Nexus et une des premières historiennes de l'art spécialiste de l'Amérique latine en France, Christine Frérot dresse un portrait intime de son appréhension du Mexique et de Cuba, des années 1970 à nos jours. Sans d'autres images que celles du récit de voyage, les douze chapitres plongent le lecteur dans un dédale saisissant de descriptions, comme si aucun adjectif ne suffisait à dépeindre les ruelles de Mexico, l'atmosphère des bars cubains et les débuts de l'aventure en Lozère. L'écrivain s'attache aussi à retranscrire le paradoxe d'un continent qui ne cesse de violenter ceux qui foulent sa terre, constamment pris entre fascination/répulsion, richesse/pauvreté, tradition/modernité, liberté/interdit, etc. Révéler sa "vérité nue» comme elle l'indique, lui permet de revenir sur sa «renaissance " latino-américaine, ou encore comment la rencontre avec l'Amérique latine a, sans cesse, forgé son identité, sa personnalité et sa carrière. Bien que son parcours latino-américain soit riche, la toile de fond de l'auteur, sa référence immuable, reste le Mexique. «Pôles confondus », Mexico et Paris deviennent son paysage intérieur, son rêve d'une rue unique reliant les deux, un « Parixico » sensible et personnel. 
2 Si le lecteur désire s'abreuver de voyages, découvrir les aventures intimes d'une universitaire passionnée ou encore appréhender le déracinement, il doit respirer ces 87 pages de souffle latino-américain.

\section{NOTES}

1. Jean Mouttapa: avant-propos de L'un vers l'autre. En voyage avec Victor Segalen, De François Cheng, 2008. 